\title{
Dual Asymmetric Centrifugation Efficiently Produces a Poloxamer-Based Nanoemulsion Gel for Topical Delivery of Pirfenidone
}

\author{
Eugene P. Chung, ${ }^{1}$ Adrienne R. Wells, ${ }^{1}$ Mia Mae Kiamco, ${ }^{1}$ and Kai P. Leung ${ }^{1,2}$
}

Received 14 May 2020; accepted 20 August 2020; published online 2 October 2020

\begin{abstract}
This study used dual asymmetric centrifugation (DAC) to produce a topical vehicle for Pirfenidone (Pf; 5-methyl-1-phenyl-2[1H]-pyridone)-a Food and Drug Administration-approved antifibrotic drug indicated for idiopathic fibrosis treatment. Pf was loaded $(8 \mathrm{wt} \%)$ in a poloxamer nanoemulsion gel (PNG) formulation consisting of water (47.8 wt \%), triacetin (27.6 wt\%), poloxamer $407(\mathrm{P} 407,13.8 \mathrm{wt} \%)$, polysorbate $80(1.8 \mathrm{wt} \%)$, and benzyl alcohol $(0.9 \mathrm{wt} \%)$. To our knowledge, poloxamer gels are typically processed with either high-shear methods or temperature regulation and have not been emulsified using DAC. Using a single-step emulsification process, 2 min mixed at 2500 RPM resulted in the lowest Pf loading variability with a relative standard deviation (RSD) of $0.96 \%$ for a $1.5 \mathrm{~g}$ batch size. Batch sizes of $15 \mathrm{~g}$ and $100 \mathrm{~g}$ yield higher RSD of $4.18 \%$ and $3.05 \%$, respectively, but still in compliance with USP guidelines. Ex vivo permeation in full thickness porcine skin after $24 \mathrm{~h}$ showed total Pf permeation of $404.90 \pm 67.07 \mu \mathrm{g} / \mathrm{cm}^{2}$. Tested in vitro on human dermal fibroblasts stimulated with transforming growth factor-beta 1 (TGF- $\beta 1$ ), Pf-PNG resulted in a $>2$ fold decrease in $\alpha$-SMA expression over vehicle control demonstrating that formulated $\mathrm{Pf}$ retained its biological activity. One-month stability testing at $25^{\circ} \mathrm{C} / 60 \%$ relative humidity (RH) and $40^{\circ} \mathrm{C} / 75 \% \mathrm{RH}$ showed that \% drug content, release kinetics, and biological activity were largely unchanged for both conditions; however, $\mathrm{pH}$ decreased from 6.7 to $5.5\left(25^{\circ} \mathrm{C} / 60 \% \mathrm{RH}\right)$ and $4.5\left(40^{\circ} \mathrm{C} / 75 \% \mathrm{RH}\right)$ after 1 month. Overall, these data demonstrate the utility of DAC to rapidly and reproducibly prepare lab-scale batches of emulsified gels for pharmaceutical formulation development.
\end{abstract}

KEY WORDS: poloxamer; dual asymmetric centrifugation; pirfenidone; antifibrotic; nanoemulsion.

\section{INTRODUCTION}

Dual asymmetric centrifugation (DAC) is a bladeless mixing process that is efficient at blending viscous materials (e.g., silicone adhesives) (1). Through a combination of centrifugal motion on a primary axis and rotational motion on a secondary axis, the wall of a DAC mixing vessel essentially acts as a shearing blade. DAC is generally reproducible and has several advantages over traditional mixing methods $(2,3)$. With no need for a central mixing component that is removed after processing, yield is improved and cumbersome cleaning procedures between batches are eliminated. Additionally, batches can be sealed,

Electronic supplementary material The online version of this article (https://doi.org/10.1208/s12249-020-01798-7) contains supplementary material, which is available to authorized users.

\footnotetext{
${ }^{1}$ Combat Wound Repair Division, United States Army Institute of Surgical Research, JBSA Fort Sam Houston, Texas 78234, San Antonio, USA.

${ }^{2}$ To whom correspondence should be addressed. (e-mail: kai.p.leung.civ@mail.mil)
}

sterilized, and processed directly into their final container closure system (4). DAC excels in processing lab-scale volumes $(<1 \mathrm{~g})(5)$ enabling high sample number, and low sample volume formulation screening studies (6-8). DAC utilization in the pharmaceutical space seems relatively novel still, but notable applications include siRNA-loaded liposomes (5), vesicular phospholipid gels (9-11), and fat emulsions (12).

Pirfenidone (Pf; 5-methyl-1-phenyl-2[1H]-pyridone; MW: $185.22 \mathrm{~g} / \mathrm{mol}$ ), which belongs to a class of medications called pyridones, is an orally active, synthetic small molecule that exhibits anti-fibrotic and anti-inflammatory properties and is approved for the treatment of idiopathic pulmonary fibrosis in Europe, Japan, and the USA (13). There has been a growing interest in broadening its treatment effects on dermal-related fibrotic diseases and other injuries (14-18). Pf has been shown to have anti-fibrotic effects in a variety of cells types, both mesenchymal and epithelial, where it is well tolerated and not cytotoxic at therapeutic doses $(19,20)$. Our group and others have demonstrated that Pf inhibits human dermal fibroblasts trans-differentiation to myofibroblasts, decreases collagen deposition and fibrosis-related gene 
expression, and reduces activation of p38 mitogen-activated protein kinase in transforming growth factor-beta 1 (TGF$\beta 1)$-stimulated human dermal fibroblasts $(21,22)$. Recently, we demonstrated that Pf can weaken the contractile machinery of activated dermal myofibroblasts (23). Using a deep partial-thickness burn model, we also observed that a Pf ointment formulation imparted a dose-dependent reduction inflammatory cytokines and alpha-smooth muscle actin $(\alpha-$ SMA) expression in mouse burn wounds (24).

We sought to formulate Pf in an alternative topical drug delivery vehicle to improve on the performance of our previous petrolatum-based ointment. We were interested in poloxamer 407 (P407) for its reported implications in burn injury and scarring. Biologically, poloxamers insert into cell membranes and can be both reparative and protective from insults (25-27). For formulation functionality, P407 is a nonionic surfactant that can act as an emulsifier, a drug solubilizer, and a viscosity enhancer and has been widely used in various pharmaceutical vehicles (28). Specifically in the topical/transdermal space, $\mathrm{P} 407$ has been notably used in pluronic lecithin organogels (PLO) $(29,30)$. Furthermore, we sought to emulsify $\mathrm{P} 407$ with an appropriate oil phase to address the prevalence of insolubilized Pf that we previously observed in our petrolatum-based ointment formulation.

In this work, we used DAC to develop and produce a poloxamer nanoemulsion gel (PNG) for topical delivery of Pf. Due to the gelling behavior of solubilized P407, processing requires high-shear methods (e.g., high-pressure homogenizer) or temperature regulation to efficiently blend a P407 gel into a final formulation (29). To our knowledge, the utility of DAC to emulsify a P407 aqueous gel has not been demonstrated. We hypothesized that DAC could be used to emulsify a room-temperature $\mathrm{P} 407$ gel with $\mathrm{Pf}$, a triacetin oil phase, a polysorbate 80 stabilizer, and a benzyl alcohol preservative. We established processing parameters to prepare ranging batch sizes $(1.5-100 \mathrm{~g})$ that are reproducible and with acceptable drug loading homogeneity. Compositional screens were performed to compare the permeation of Pf in ex vivo full thickness porcine skin. Furthermore, we demonstrated that the formulation maintained the in vitro dermal anti-fibrotic activity of Pf. Lastly, we characterized the compositional stability in regard to in vitro drug release, $\mathrm{pH}$, viscosity, \% drug content, and droplet size.

\section{MATERIALS AND METHODS}

\section{Materials}

P407, triacetin, propylene glycol, polyethylene glycol (PEG) 400, oleyl alcohol, octyldodecanol, medium chain triglyercides, isopropyl myristate, cocoyl caprylocaprate, decyl oleate, and pyrrolidone were kindly provided by BASF (Florham Park, NJ, USA). Pf (99\%, HPLC) was purchased from AK Scientific (Union City, CA, USA). Benzyl alcohol, dimethyl sulfoxide, potassium phosphate monobasic $\left(\mathrm{KH}_{2} \mathrm{PO}_{4}\right)$, mouse monoclonal antibody against GAPDH (1:500, clone 6C5), Triton X-100, and Tween 20 were purchased from MilliporeSigma (Burlington, MA, USA). HPLC-grade water, acetonitrile, and methanol were purchased from Fisher Scientific (Hampton, NH, USA). S600 oil was purchased from Canon Instrument Company (State
College, PA, USA). Regenerated cellulose membranes (MWCO 12-14 kDa) were purchased from Repligen (Waltham, MA, USA). Porcine skins were commercially purchased from Midwest Research Swine (Gibbons, MN, USA). Stocks of adult normal human dermal fibroblast cells (NHDF) from two separate donors were purchased from PromoCell (Heidelberg, Germany). Ten percent fetal bovine serum was purchased from HyClone, GE Healthcare Life Sciences (Issaquah, WA, USA). Recombinant human TGF$\beta 1$ was purchased from R\&D Systems (Minneapolis, MN, USA). Paraformaldehyde (4\%) was purchased from Electron Microscopy Sciences (Hatfield, PA, USA). Mouse monoclonal antibody against $\alpha$-SMA (clone 1A4) was purchased from Abcam (Cambridge, MA, USA). Gibco normal goat serum, Dulbecco's modified Eagle's medium, penicillin-streptomycin, Hoechst 33342, Pierce RIPA buffer, Pierce EDTA-free protease inhibitors mini tablets, Pierce BCA assay, ProLong Diamond mounting solution, Alexa Fluor 488-conjugated goat anti-mouse secondary antibody, and TRITC-conjugated phalloidin were purchased from Thermo Fisher Scientific (Waltham, MA, USA).

\section{Poloxamer Nanoemulsion Gel Preparation}

A stock of aqueous $30 \mathrm{wt} \%$ (g/g) P407 was pre-prepared by Eurostar 60 overhead mixing (IKA, Staurfen, Germany) with ice water. The nanoemulsion gel was additionally composed of triacetin, polysorbate 80 , and benzyl alcohol (Table I). To prepare a batch, all ingredients were dispensed individually using a Repeater E3x electronic positive displacement dispenser (Eppendorf, Hamburg, Germany) calibrated to each ingredient's liquid density. Briefly, a $30 \mathrm{wt} \%$ Poloxamer gel, chilled on ice to liquefy, was dispensed into a mixing cup and allowed to gel at room temperature. All other ingredients were dispensed appropriately, including the Pf powder. A mixing cup was capped and mixed on a SpeedMixer ${ }^{\mathrm{TM}}$ 150.1 FVZ dual asymmetric centrifuge (DAC) (FlackTek Inc., Landrum, USA). Parameter optimization included varying mix speed $(1500,2500$, and 3500 $\mathrm{RPM}$ ) and time $(1,2$, and $5 \mathrm{~min})$. Due to a $1 \mathrm{~min}$ limit on the equipment, extended mix times are the result of multiple 1min spins. Batches were reproduced to $n=3$, except for $100 \mathrm{~g}$ batch sizes which was prepared $n=1$ due to drug costs. Penetration enhancers (cocoyl caprylocaprate, dimethyl sulfoxide, decyl oleate, isopropyl myristate, octyl dodecanol, pyrrolidone, propylene glycol) were also evaluated at $5 \mathrm{wt} \%$ of the vehicle in replacement of a proportional amount of water.

Table I. Composition of Poloxamer-Based Nanoemulsion gel (PNG)

\begin{tabular}{lll}
\hline Component & Function & wt $\%$ \\
\hline Water & Water phase & $47.8 \%$ \\
Triacetin & Oil phase & $27.6 \%$ \\
Poloxamer 407 & Viscosity enhancer/emulsifier & $13.8 \%$ \\
Polysorbate 80 & Co-emulsifier & $1.8 \%$ \\
Benzyl alcohol & Preservative & $0.9 \%$ \\
Pirfenidone & API & $8 \%$ \\
\hline
\end{tabular}




\section{uHPLC Quantification of Pirfenidone}

Pf was quantified by uHPLC (Vanquish ${ }^{\mathrm{TM}}$ Flex Quarternary, Thermo Scientific, Karlruhe, Germany) equipped with an INTERSIL ODS2 (150 ̊, $5 \mu \mathrm{m}, 4.6 \mathrm{~mm} \times$ $250 \mathrm{~mm}) \mathrm{C} 18$ column. Mobile phase consisted with 65:35 ratio of $0.02 \mathrm{M}, \mathrm{pH} 2.5 \mathrm{KH}_{2} \mathrm{PO}_{4}$ in water:acetonitrile in isocratic mode with a flow rate of $1 \mathrm{~mL} / \mathrm{min}$ and injection volume of $20 \mu \mathrm{L}$. The temperature was maintained at $30^{\circ} \mathrm{C}$ by air circulation in the column compartment, and Pf was detected at a wavelength of $310 \mathrm{~nm}$ with a retention time of approximately $9 \mathrm{~min}$. The concentrations of unknowns were determined by comparing against a standard curve ranging from 3.9 to $500 \mu \mathrm{g} / \mathrm{mL}$ (Supplemental $1, R^{2}=1.000$, limit of detection $(\mathrm{LOD})=1.146 \mu \mathrm{g} / \mathrm{mL}$, limit of quantification $(\mathrm{LOQ})=3.472 \mu \mathrm{g} / \mathrm{mL})$.

\section{Drug Uniformity}

Drug loading of Pf was determined by sampling from three different areas of every batch produced. Samples were diluted $100 \times$ in a 1:1 mixture of methanol:water and stirred for $1 \mathrm{~h}$. Samples were syringe-filtered with a $0.44-\mu \mathrm{m}$ PTFE membrane and ran on an uHPLC.

\section{Droplet Sizing}

Dynamic light scattering (DLS) was used to determine nanoemulsion droplet sizing on a Zetasizer Nano ZS (Malvern Panalytical, Almelo, Netherlands). Nanoemulsion was diluted $500 \times$ in $10 \mathrm{mM}$ potassium chloride $(\mathrm{KCl})$ with vortexing. No significant difference in size measurement was observed when diluted 10-1000x, or by resuspension method of vortexing or stir bar (data not shown).

\section{Rheometry}

Rheological measurements for nanoemulsion samples were performed using a Haake MARS III (Thermo Scientific, Karlsruhe, Germany). A 20-mm diameter titanium parallel plate was used as a measuring geometry. All measurements were performed at $22^{\circ} \mathrm{C}$, which was controlled by using a Haake 10 water bath (Thermo Scientific, Karlsruhe, Germany), and recorded 1 day after preparation, then every week (for the $100 \mathrm{~g}$ batch) over 1 month as part of the stability test. Briefly, $400 \mu \mathrm{L}$ of nanoemulsion sample was dispensed onto the surface of the lower plate. Then, the upper plate was lowered to a gap of $1 \mathrm{~mm}$. Excess sample was removed by scrapping the edges of the plate using a disposable spatula. Four sequential steps were performed for rheological characterization. Step 1: The samples were allowed to relax from stress accumulated from loading by performing an oscillation time sweep test for $10 \mathrm{~min}$ (at strain, $\gamma=0.1 \%$ and frequency, $\omega=1 \mathrm{~Hz}$ ). Step 2: An oscillation stress sweep test was done $(\gamma=0.001-50 \%, \omega=1 \mathrm{~Hz})$ to determine the linear viscoelastic region (LVER) for step 3. Step 3: An oscillation frequency sweep test was performed $(\gamma=0.01 \%, \omega=1-100 \mathrm{~Hz})$ to characterize the nanoemulsion formulation. Step 4: Finally, a steady state rotation step was performed (shear rate from $0.00021 / \mathrm{s}$ to $501 / \mathrm{s}$ ) to obtain the relationship between viscosity and shear rate. We report the zero-shear viscosity obtained from step 4 as part of the 1month stability test. Zero-shear viscosity is the maximum plateau value obtained at very low shear rates; this is the viscosity of the formulation at rest. Furthermore, Ostwald-de Waele model was used for fitting the plot between shear stress $(\tau)$ and shear rate $\left(\frac{\partial u}{\partial y}\right)$; this model gives the value of consistency index $(K)$ and flow behavior index $(n)$.

$\tau=K\left(\frac{\partial u}{\partial y}\right)^{n}$

S600 oil was used as a viscosity standard to verify the accuracy of rheometer (Supplemental 2). Briefly, $400 \mu \mathrm{L}$ of S600 oil was dispensed on the lower parallel plate. Then the upper plate was lowered to a gap of $1 \mathrm{~mm}$. The shear rate was varied from 0.1 to 1000 1/s, and shear stress was measured via rotation step (stage temperature used was $20^{\circ} \mathrm{C}$ ). Based on the plot in Supplemental 2, shear rate vs shear stress plot resulted in a linear relationship with $\mathrm{R} 2$ value of 0.9989 and slope (dynamic viscosity) of $1.567 \mathrm{mPa}$-s (reported manufacturer value is 1.594 at $20^{\circ} \mathrm{C}$ ).

\section{In Vitro Release Test}

In vitro release tests (IVRT) were performed on a vertical diffusion cell (Vision ${ }^{\circledR}$ Microette ${ }^{\mathrm{TM}}$, Hanson, Chatsworth, CA, USA) with automated sampling. Diffusion cells had an effective diffusion area of $1.77 \mathrm{~cm}^{2}$ and a donor chamber height of $1 \mathrm{~mm}$. Donor chamber was separated from receptor chamber with a regenerated cellulose membrane of MWCO 12-14 kD. Receptor chamber was $6.7 \mathrm{~mL}$ in volume and filled with $1 \times$ phosphate-buffered saline (PBS) at $\mathrm{pH} 7.4$ and maintained at $32^{\circ} \mathrm{C}$ using a recirculating water bath. A total of $500 \mu \mathrm{L}$ samples were taken at $1,2,3,4,6,8,12,18$, and $24 \mathrm{~h}$ which involved a $1 \mathrm{~mL}$ flush followed by a sampling event. Pf concentration in all samples was quantified by uHPLC.

\section{Ex Vivo Deposition in Porcine Skin}

Deposition of Pf (8 wt\%) from different compositions was screened on commercially sourced full-thickness porcine skin from Midwest Research Swine (Gibbon, MN, USA). Uncompromised skin visually free of redness or blemishes was collected at 3-mm thickness from the back of a single donor and shipped on ice by the supplier. Once received, skins were first frozen at $-20^{\circ} \mathrm{C}$ before being die press cut at $3 / 4^{\prime \prime}$ diameter to fit our custom vertical diffusion cell adapter and stored at $-20^{\circ} \mathrm{C}$ until use. The adapter consists of a lip that applies downward pressure on the outside edges of the skin to limit formulation leakage. At the time of the experiment, frozen skins were inserted into the skin adapter with effective diffusion area of $1.77 \mathrm{~cm}^{2}$ and mounted on a diffusion cell that was set to $37^{\circ} \mathrm{C}$. The receptor was filled with $1 \times$ PBS containing 0.05 wt $\%$ gentamycin to limit microbial growth. Skins were equilibrated to room temperature for $1 \mathrm{~h}$ before applying formulation to the donor chamber. PNG samples with chemical penetration enhancers at $5 \mathrm{wt} \%$ or without were separately tested and applied as a 1-mm-thick layer (approximately $200 \mathrm{mg}$ ) to 
assess the effect on Pf deposition in skin. The system was occluded and allowed to sit for $24 \mathrm{~h}$, and then the skin and receptor fluid were collected. The surface of the skin was wiped with an alcohol wipe to remove residual formulation from the donor phase. Pf was extracted from intact skin by incubating in $10 \mathrm{~mL}$ of methanol for $24 \mathrm{~h}$ at $50^{\circ} \mathrm{C}$ in a sealed, $20 \mathrm{~mL}$ glass scintillation vial to minimize solvent evaporation. All skin extracts and receptor fluids were syringe-filtered with a $0.44 \mu \mathrm{m}$ nylon membrane prior to quantification by uHPLC.

\section{In Vitro Biological Activity Assay in TGF $\beta-1$ Human Dermal Fibroblasts}

Normal human dermal fibroblasts (NHDF) were maintained in complete media (DMEM, 10\% FBS, $1 \%$ penicillinstreptomycin), and experiments were performed using cells cultured within 8 passages. Cell assays were performed as previously described (21). For both immunocytochemistry and Western blot assays, cells were seeded in complete media and grown for at least $24 \mathrm{~h}$ before serum starvation in serumfree media (SFM) with $1 \%$ penicillin-streptomycin. After $24 \mathrm{~h}$ in SFM, cells were treated with $10 \mathrm{ng} / \mathrm{ml} \mathrm{TGF}-\beta 1$ with or without Pf $(0.5 \mathrm{mg} / \mathrm{ml})$. Fresh Pf solution dissolved in $1 \times$ PBS was compared with Pf released from gel preparations into PBS. Pf extraction consisted of dialyzing vehicle or vehicle with drug in a regenerated cellulose dialysis tube (MWCO 12$14 \mathrm{kDa})$ and collecting the release fractions after incubation at $37^{\circ} \mathrm{C}$ for $24 \mathrm{~h}$ with rocking. The concentration of fresh and released Pf was verified by uHPLC before solutions were filter sterilized $(0.22 \mu \mathrm{m})$.

\section{Immunocytochemistry and Confocal Imaging}

NHDF were seeded at 2500 cells per well in 8-well chambered slides (Nunc Lab-Tek, Thermo Scientific). Serumstarved cells were treated with $10 \mathrm{ng} / \mathrm{ml}$ TGF- $\beta 1$ and vehicle or gel-released Pf $(0.5 \mathrm{mg} / \mathrm{ml})$ and cultured for 4 days before fixation for $20 \mathrm{~min}$ in $4 \%$ paraformaldehyde. After $10 \mathrm{~min}$ permeabilization in $0.1 \%$ Triton $\mathrm{X}-100$ and $1 \mathrm{~h}$ blocking with $10 \%$ normal goat serum, $0.1 \%$ Tween 20 in PBS, slides were incubated for $1.5 \mathrm{~h}$ at room temperature in primary antibody diluted in blocking solution (1:100, mouse monoclonal against $\alpha$-SMA, clone 1A4). After three 5 min rinses in PBT $(0.1 \%$ Tween 20 in PBS), slides were incubated for $1 \mathrm{~h}$ at room temperature with secondary antibody Alexa Fluor 488conjugated goat anti-mouse (1:1000), TRITC-conjugated phalloidin (1:40), and Hoechst 33342 (1:2000). All dilutions were prepared using the blocking solution. Slides were mounted with ProLong Diamond mounting solution. Confocal images were acquired with a Plan-Apochromat $10 \times, 0.45$ NA objective on a Zeiss 710 confocal microscope (Zeiss, Thornwood, NY). The same laser power, gain, and digital offset were used for all slides. Image montages were prepared in ImageJ (National Institutes of Health, Bethesda, MD).

\section{Western Blot Analysis}

NHDF were seeded in complete media at $8 \times 10^{4}$ cells per well in 6-well tissue culture plates and grown to $70 \%$ confluence before $24 \mathrm{~h}$ serum starvation and subsequent treatment. NHDF were directly lysed on the culture plate in
Pierce RIPA buffer supplemented with Pierce EDTA-free protease inhibitors mini tablets. Plates were then scraped to collect whole cell lysates before samples were clarified by centrifugation at $14,000 \mathrm{RPM}$ for $15 \mathrm{~min}$ at $4^{\circ} \mathrm{C}$. Protein concentration was quantified using the Pierce BCA assay. Immune detection of proteins was performed using the Simple Wes capillary-based Western blot technology as described previously (31) (Protein Simple, San Jose, CA). Briefly, samples were adjusted to equivalent protein concentration using provided sample buffer; four-part protein sample was mixed with one part provided $5 \mathrm{X}$ master mix (Protein Simple) containing fluorescent molecular weight markers and DTT $(40 \mathrm{mM})$. Samples were heated at $95^{\circ} \mathrm{C}$ for $5 \mathrm{~min}$ prior to loading into supplied microplate. Primary antibodies for $\alpha$-SMA (1:20) and GAPDH (1:500) were diluted in provided antibody diluent and added to microplate along with provided HRP-conjugated secondary antibody, chemiluminescent substrate and wash buffer. The automated capillary system, Simple Wes, separated the proteins by electrophoresis, immobilized the proteins, and then performed immunoblotting in the same capillary. Protein quantification was performed using the Compass software for Simple Western (v3.0.9; Protein Simple).

\section{Formulation Stability}

Formulation stability was monitored over the course of 1 month at normal $\left(25^{\circ} \mathrm{C} / 60 \% \mathrm{RH}\right)$ and accelerated $\left(40^{\circ} \mathrm{C} /\right.$ $75 \% \mathrm{RH})$ conditions as outlined by ICH Q1A(R2). Formulation $\mathrm{pH}$, viscosity, drug content, and droplet size were measured at days $0,7,14,21$, and 28 . The effect of storage on IVRT was assayed at 28 days. $\mathrm{pH}$ was determined by diluting the formulation $10 \times$ in filtered HPLC water and measuring with a SevenExcellence $\mathrm{pH}$ meter configured with an InLab Expert PRO-ISM pH electrode (Mettler Toledo, Columbus, $\mathrm{OH}$, USA). All other characterization was performed as detailed previously.

\section{Statistical Analysis}

All data analysis was done on GraphPad Prism 8 software. Statistical significance of differences in drug homogeneity was determined with a two-way ANOVA followed with post hoc testing at a confidence level of 0.05 . Differences in $\mathrm{Pf}$ permeation for various penetration enhancers were evaluated by the Student's $t$ test with a confidence level of 0.05 . Statistical significance for in vitro activity assay was determined by one-way ANOVA followed with Bonferroni post-test at a confidence level of 0.01 . All results are reported as average \pm standard deviation (stdev).

\section{RESULTS}

\section{Processing Parameter Determination}

We initially optimized DAC processing parameters using a small, $1.5 \mathrm{~g}$ batch size. The time and mixing speeds were the primary setting inputs for DAC, and we wanted to establish a working range that could effectively dissolve Pf and emulsify pre-solubilized $\mathrm{P} 407$ gel with additional excipients in a single step. We tested variations to mixing speed $(1500,2500$, and 
3500 RPM) and time (1, 2, and $5 \mathrm{~min}$ ) using the drug homogeneity as the primary criterion of acceptability according to USP standards: $<6 \%$ relative standard deviation and no individual samples outside $10 \%$ of the label. Three individual batches were produced for each setting combination.

Descriptively, the PNG produced by DAC was white in color, smooth, non-flowing, and bubble-free (Fig. 1a). After altering mixing speed and time for a $1.5 \mathrm{~g}$ batch size, a twoway analysis of variance (ANOVA) revealed that speed $(F(2,72)=2.997, p=0.06)$ impacted drug homogeneity more than mix time $(F(2,72)=0.534, p=0.60)$. By increasing mix speeds over $1500 \mathrm{RPM}$, there was a noticeable tightening distribution of samplings for drug loading (Fig. 1b). For example, comparing a 2 min mix at 1500 RPM to 2500 RPM resulted in improved drug loading uniformity with standard deviations of $2.79 \%$ and $0.96 \%$, respectively. While a $1 \mathrm{~min}$ spin was enough to meet USP guidelines on drug homogeneity, immediate observation under cross-polarized microscopy showed the presence of insolubilized Pf (Fig. 1c). This was true for all mix speeds, but Pf was fully dissolved by increasing mix time to $2 \mathrm{~min}$ and over. For further experiments, we used a 2500 RPM mix speed for 2 min to minimize process time and avoid potential over-mixing.

\section{Batch Size Processing}

A major advantage of DAC is the feasibility to produce small batch sizes that are difficult to process with traditional mix methods. Smaller batches can result in cost saving when scouting process settings and screening compositions. Using a $1.5 \mathrm{~g}$ batch size, we identified that a $2500 \mathrm{RPM}$ mix for $2 \mathrm{~min}$ can simultaneously emulsify the vehicle and homogenously distribute Pf. Maintaining the same process settings, $1.5 \mathrm{~g}$,
$15 \mathrm{~g}$, and $100 \mathrm{~g}$ batch sizes were produced and their drug homogeneity and rheological properties were compared for further characterization studies.

Compared with a $1.5 \mathrm{~g}$ batch size, $15 \mathrm{~g}$ and $100 \mathrm{~g}$ batches showed a broader distribution of drug loading measurements when sampled across different areas of the mixing cup (Fig. 2a). This indicated that larger batches may require either longer mix times and/or faster mix speeds in order to compensate for the larger volume of material that Pf must be dispersed into. In this preliminary scalability evaluation, we demonstrate the same setting can apply to batch sizes from 15 to $100 \mathrm{~g}$ with drug loadings of $8.30 \pm 0.35 \mathrm{wt} \%$ ( $4.18 \%$ RSD) and $8.41 \pm 0.26 \mathrm{wt} \%$ (3.05\% RSD), passing USP guidelines on drug uniformity.

In addition to measuring drug loading and homogeneity, we added rheological characterization to compare PNGs produced at ranging batch sizes. The rheological evaluation showed that viscosities were comparable across the three batch sizes (Fig. 2b). Moreover, the dependence of viscosity with shear rate and its flow behavior was consistent with a non-Newtonian pseudoplastic material. This is typical for a concentrated emulsion formulation such as our PNG (32). Moreover, when shear stress vs shear rate plots were fitted with Ostwald-de Waele model (power law), the flow behavior index $(n)$ gave a value of less than 1 for all batch sizes, which is indicative of a pseudoplastic type of fluid (Supplemental 3A). In addition, a horizontal-parallel behavior between storage modulus $\left(\mathrm{G}^{\prime}\right)$ and loss modulus $\left(\mathrm{G}^{\prime \prime}\right)$ with $\mathrm{G}^{\prime}$ (elastic contribution) being larger in value than $G^{\prime \prime}$ (viscous contribution) (Supplemental 3B) indicated that the PNG had a gellike consistency (i.e., elastic-like behavior); this plateau region is indicative of an entangled polymer system. At this plateau region, the PNG reached stability at rest due to no flow and behaved like a solid substance. Moreover, tan delta values a

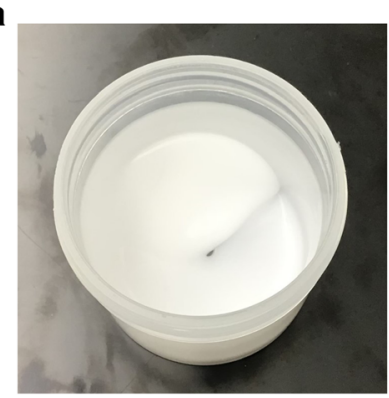

C

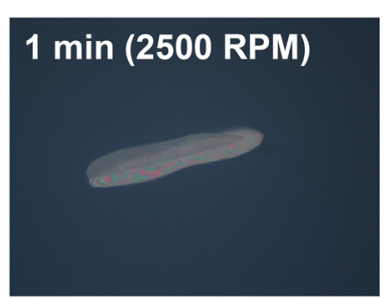

b
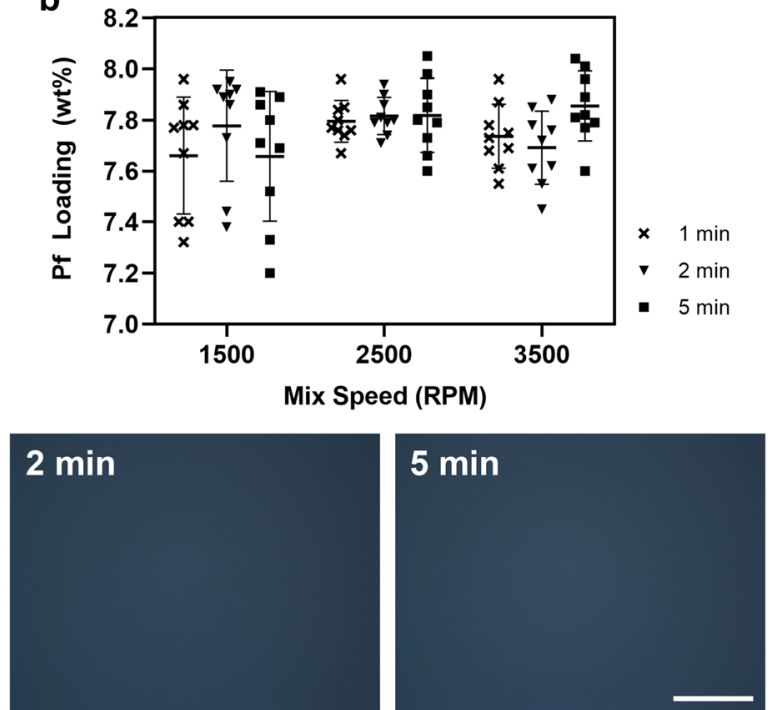

Fig. 1. DAC parameter optimization for mix speed (1500, 2500, and $3500 \mathrm{RPM})$ and mix time (1, 2 , and $5 \mathrm{~min}$ ). a PNG is visually white, smooth, non-flowing, and free of bubbles. b Drug loading and homogeneity were measured and showed tight distribution of samples when processed at 2500+ RPM. c Representative cross-polarized microscopy images show presence of undissolved Pf when mixed for only $1 \mathrm{~min}$, but not at $2+$ min when processed at $2500 \mathrm{RPM}$. Scale bar is $100 \mu \mathrm{m}$. $n=3$ batches, 3 samples per batch. Standard deviation bars = avg. \pm stdev 

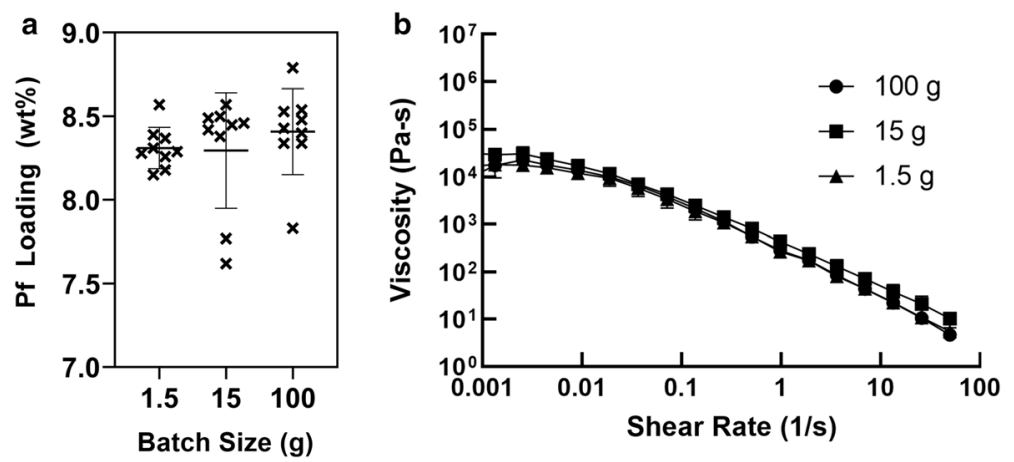

Fig. 2. Batch size processing. With a constant processing setting of 2500 RPM for $2 \mathrm{~min}, 1.5,15$, and $100 \mathrm{~g}$ batch sizes were characterized to determine a drug loading and homogeneity and $\mathbf{b}$ viscosity. Standard deviation bars $=$ avg. \pm stdev

(the ratio between $\mathrm{G}^{\prime}$ and $\mathrm{G}^{\prime \prime}$ ) at this region showed values less than 1 for all batch sizes (Supplemental 4). Hence, the formulation retains its structure at rest without sedimentation or separation of phases. This was true for a range of frequencies, but as the frequency was increased, both $G^{\prime}$ and $G^{\prime \prime}$ increased, and $G^{\prime \prime}$ approached $G^{\prime}$, indicating that the force applied is higher than the microstructure forces. This leads to the collapse of the microstructure and the material starts to flow. At high frequencies, the PNG started to exhibit fluid-like behavior conducive to application on surface. These observations were consistent across batch sizes.

\section{Ex Vivo Porcine Skin Deposition of Pf}

A panel of PNGs containing $8 \mathrm{wt} \%$ Pf and different chemical penetration enhancers was tested by applying a 1mm-thick layer of PNG on a full thickness porcine skin (3 mmthick, $1.77 \mathrm{~cm}^{2}$ effective area) to assess differences in Pf deposition. Chemical penetration enhancers (PEs) were added at $5 \mathrm{wt} \%$. This assay was used to measure Pf retention in full thickness skin as opposed to the more traditional in vitro permeation test (IVPT) in which pass through is only measured across thinly dermatomized skin. We found that after $24 \mathrm{~h}$, the base composition resulted in a total of $404.90 \pm$ $67.07 \mu \mathrm{g} / \mathrm{cm}^{2}$ of Pf permeated into the skin, $252.26 \pm 48.51 \mu \mathrm{g} /$ $\mathrm{cm}^{2}$ retained in the tissue, and $152.64 \pm 46.32 \mu \mathrm{g} / \mathrm{cm}^{2}$ measured in the receptor (Fig. 3). Among the tested PEs, the highest permeation in the skin was associated with dimethyl sulfoxide $\left(440.70 \pm 50.95 \mu \mathrm{g} / \mathrm{cm}^{2}\right)$ and pyrollidone $\left(475.83 \pm 107.99 \mu \mathrm{g} / \mathrm{cm}^{2}\right)$, both aprotic solvents known to readily permeate through skin, but the increases were not statistically significant over baseline by Student's $t$ tests. Pf is a small molecule that has been previously demonstrated to permeate through skin with an optimized liposomal formulation resulting in $\sim 500 \mu \mathrm{g} / \mathrm{cm}^{2}$ cumulative permeation

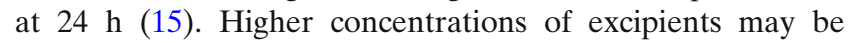
explored in the future to further enhance Pf delivery. We opted to continue characterization efforts with the baseline composition because the baseline was performed as well as formulations containing PEs in our initial screen.

\section{In Vitro Biological Activity of Gel-Released Pf}

Immunocytochemistry and protein expression analysis confirmed that Pf released from the PNG formulation retained its biological activity and inhibited myofibroblast differentiation (Fig. 4). Just as with the fresh Pf solution prepared from powder, the formulation-released Pf solution inhibited $\alpha$-SMA expression and F-actin stress fiber formation (Fig. $4 a, b$ ). Although the TGF- $\beta 1+$ vehicle treated samples showed lower $\alpha$-SMA expression, there was a distinct further reduction of $\alpha$-SMA expression with Pf released from the formulation. The protein expression analysis performed by Simple Wes capillary electrophoresis and immunodetection confirmed the immunocytochemistry results (Fig. 4c).

\section{Stability Assessment}

IVRT was performed to determine release profiles of Pf from PNGs and to assess the stability when stored at normal $\left(25^{\circ} \mathrm{C} / 60 \% \mathrm{RH}\right)$ and accelerated $\left(40^{\circ} \mathrm{C} / 75 \% \mathrm{RH}\right)$ conditions. Pf was released in a biphasic profile with a linear cumulative release out to $8 \mathrm{~h}$, followed by a slower linear release out to $24 \mathrm{~h}$ (Fig. 5). Batches stored for 1 month at both conditions showed comparable release profiles to a freshly prepared

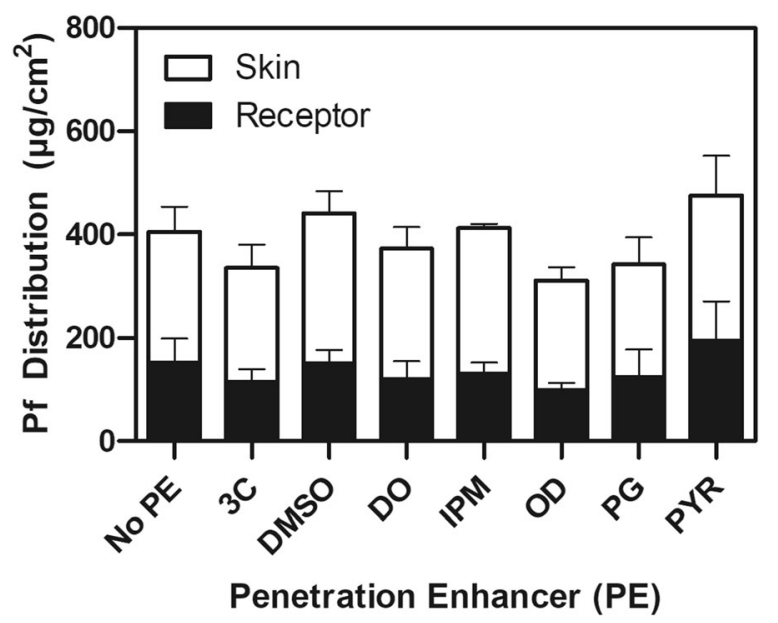

Fig. 3. Effect of chemical penetration enhancers (PE) on Pf deposition in ex vivo porcine skin after $24 \mathrm{~h}$. Cumulative $\mathrm{Pf}$ permeation was measured from skin extracts (white bar) and the receptor chamber (black bars). Cocoyl caprylocaprate (3C), dimethyl sulfoxide (DMSO), decyl oleate (DO), isopropyl myristate (IPM), octyldodecanol (OD), propylene glycol (PG), and pyrrolidone (PYR) were added at $5 \mathrm{wt} \%$ of the formulation. $n=3$, single skin donor; standard deviation bars $=$ avg. \pm stdev 

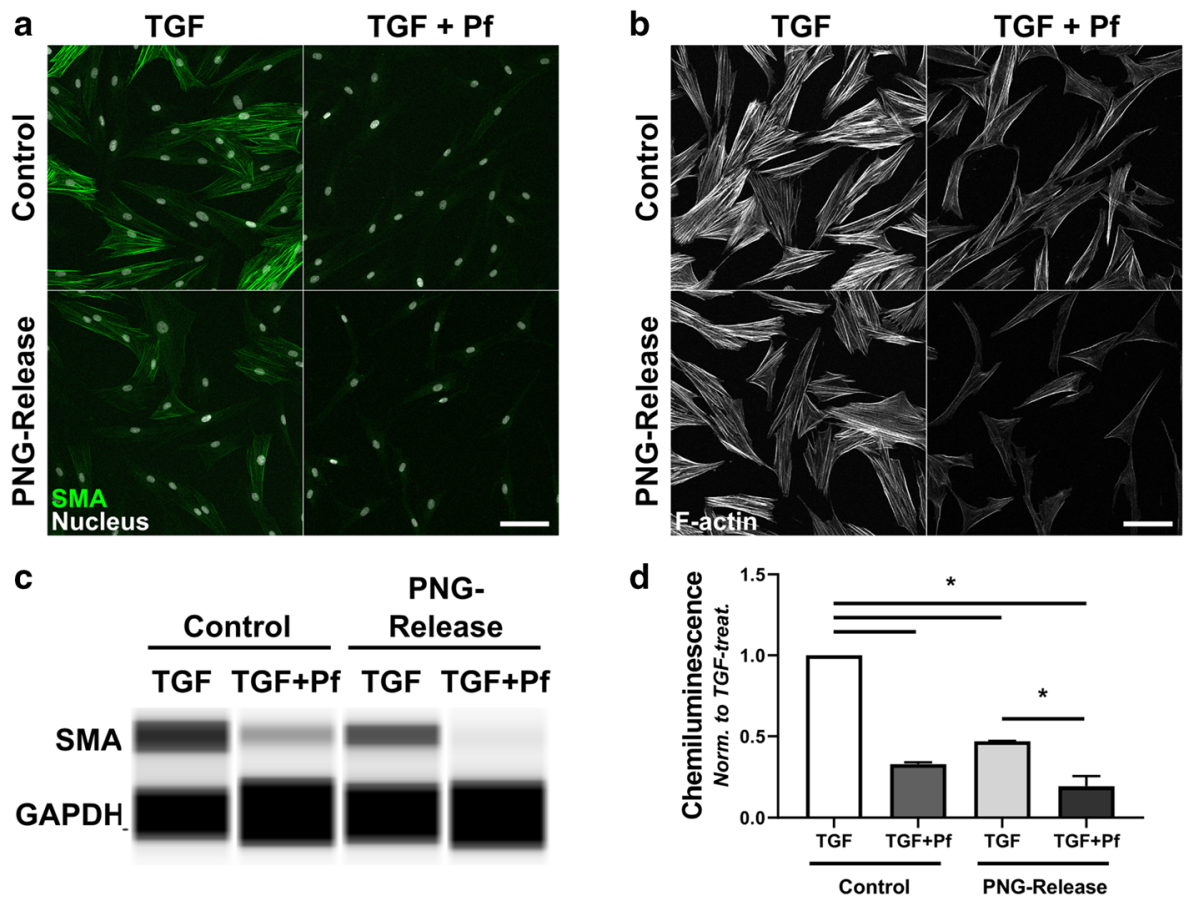

Fig. 4. Pf retains biological activity in a PNG formulation. Fibroblasts were treated for 4 days with TGF- $\beta 1$ alone (TGF, Control), TGF- $\beta 1$ + Pf from powder in PBS (TGF + Pf, Control), TGF- $\beta 1$ with vehicle release from blank PNG (TGF, PNG-Release), or TGF- $\beta 1$ with Pf release from PNG (TGF + Pf, PNG-Release). a Fixed cells immunostained for $\alpha$-SMA (green, SMA) and for nuclei with Hoechst (white, Nucleus). b Same treatments as in (a), F-actin stress fibers labeled with fluorescent phalloidin (F-actin). Scale bars are $100 \mu \mathrm{m}$. c, d Whole cell lysates were collected from fibroblasts treated as above and probed for $\alpha$-SMA protein expression. c Pseudogel image of individual capillaries run on Simple Wes system probed for $\alpha$-SMA and GAPDH. d Plots show avg. \pm stdev from 2 donors, normalized to TGF-alone for each donor. $\alpha$-SMA protein normalized to GAPDH probed in same capillary. ${ }^{*} P<0.01$ with one-way ANOVA and Bonferonni post-test

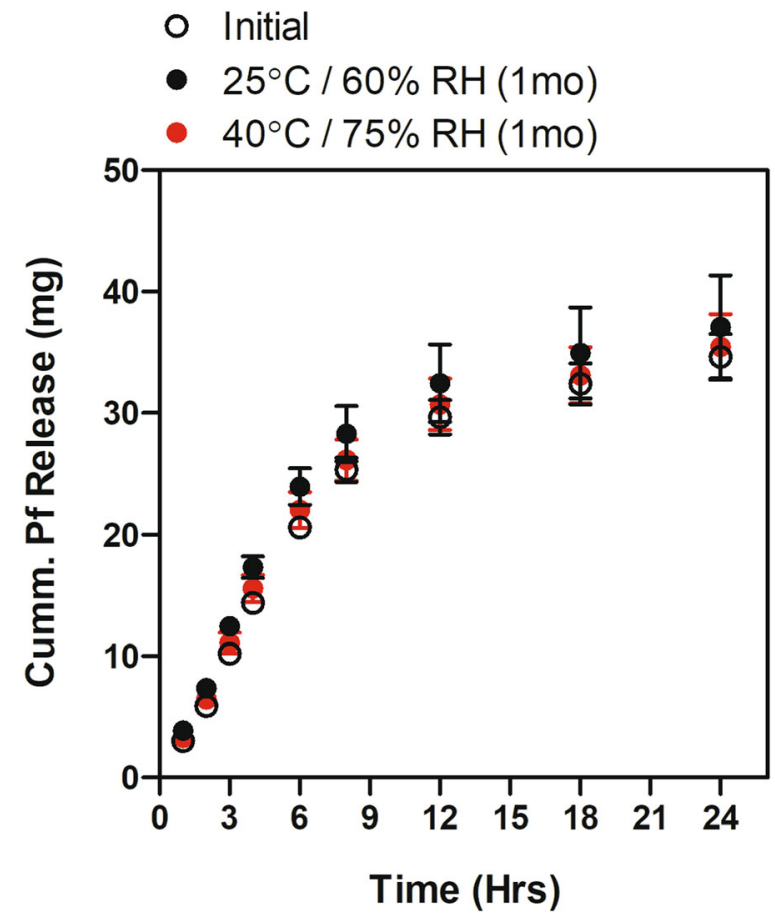

Fig. 5. IVRT of Pirfenidone from PNGs. Release profiles were measured for freshly prepared formulation as well as formulations stored for 1 month at $25^{\circ} \mathrm{C} / 60 \% \mathrm{RH}$ and $40^{\circ} \mathrm{C} / 75 \%$ RH. $n=3$; standard deviation bars $=$ avg. \pm stdev batch. Notably, we observed that the PNG within the donor chamber becomes completely clear within $6 \mathrm{~h}$ (data not shown) which we suspect is due to the dissolution of the oil phase into the receptor phase as triacetin is slightly water soluble $(60 \mathrm{~g} / \mathrm{L})(33)$.

The 1 month stability of our PNG composition was also assessed by $\mathrm{pH}$, viscosity, drug content, and droplet size when stored at normal $\left(25^{\circ} \mathrm{C} / 60 \% \mathrm{RH}\right)$ and accelerated $\left(40^{\circ} \mathrm{C} / 75 \%\right.$ $\mathrm{RH}$ ) conditions (Fig. 6a-d). Initial $\mathrm{pH}$ of the PNG was measured at 6.7 with marked decreases within 1 week, showing continued $\mathrm{pH}$ drop to $5.5\left(25^{\circ} \mathrm{C} / 60 \% \mathrm{RH}\right)$ and 4.5 $\left(40^{\circ} \mathrm{C} / 75 \% \mathrm{RH}\right)$ after 1 month (Fig. 6a). Observations of $\mathrm{pH}$ drop initially correlated with decreased viscosity over time; zero-shear viscosity decreased from $19.2 \pm 3.0 \mathrm{MPa}$-s to $13.9 \pm$ $1.5 \mathrm{MPa}$-s after 1 month storage at $25^{\circ} \mathrm{C} / 60 \% \mathrm{RH}$, whereas it decreased from $19.2 \pm 3.0 \mathrm{MPa}$-s to $14.5 \pm 1.8 \mathrm{MPa}-\mathrm{s}$ after 2 weeks of storage at $40^{\circ} \mathrm{C} / 75 \% \mathrm{RH}$ but recovered at 1 month (Fig. 6b). Droplet sizing was initially $\sim 20 \mathrm{~nm}$, and for both storage conditions, significantly increased to $\sim 250 \mathrm{~nm}$ within 1 week (Fig. 6d). Droplet size appeared to stabilize after 1 week and was relatively constant out to 1 month.

While these trends indicate dynamic changes to the formulation that can potentially impact biological efficacy, we observed no effect on drug content and biological activity of Pf. After 28 days, compared with a day 0 baseline, drug loading measurements showed $98.5 \pm 1.3 \%\left(25^{\circ} \mathrm{C} / 60 \% \mathrm{RH}\right)$ 

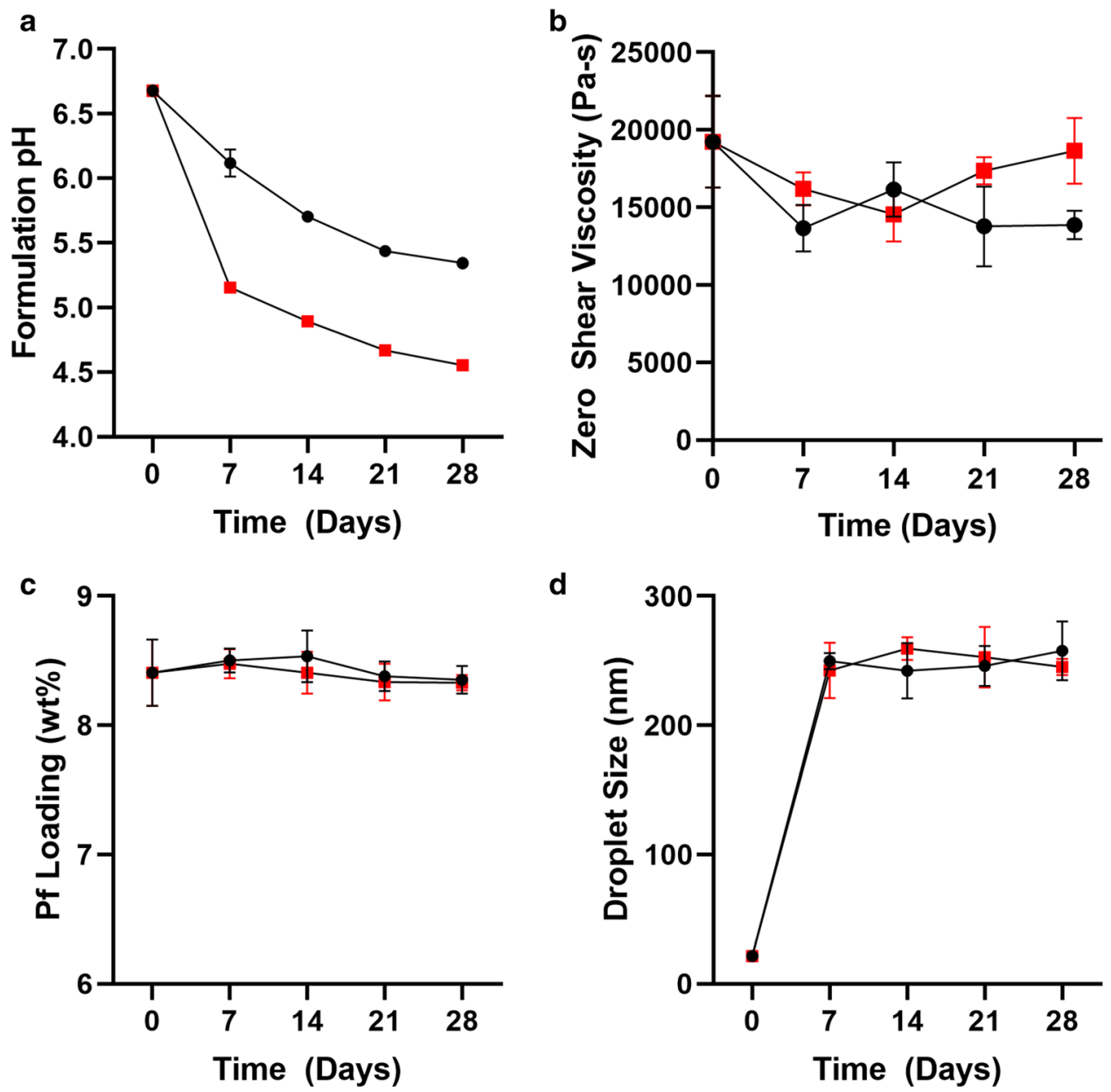

d
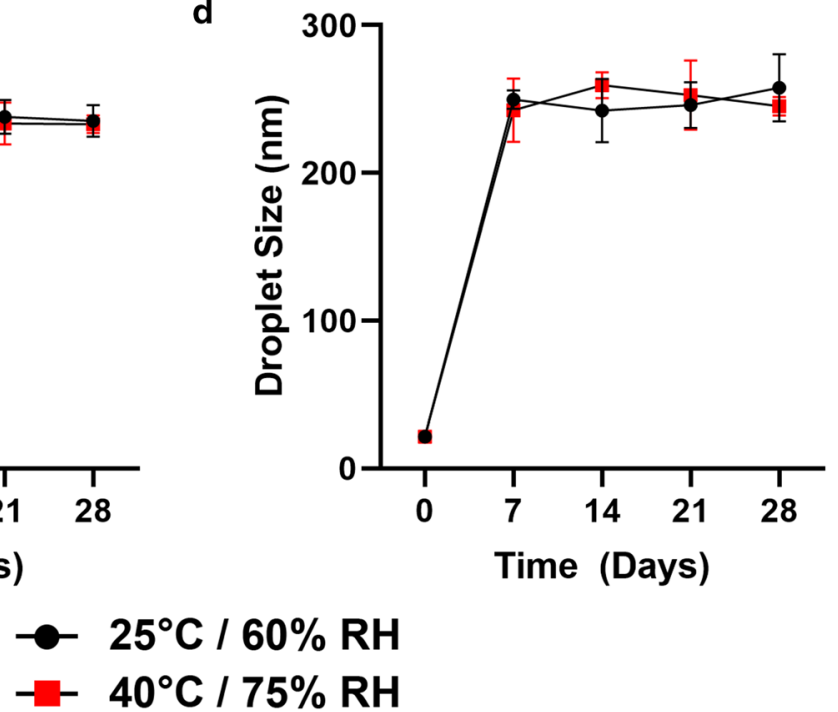

Fig. 6. One-month stability assessment of PNG formulations. Stability was determined by a formulation $\mathrm{pH}, \mathbf{b}$ viscosity at rest (zero-shear), $\mathbf{c} \%$ drug content of day 0 loading, and d droplet size. $N=3$; standard deviation bars $=$ avg. \pm stdev

and $98.2 \pm 0.8 \%\left(40^{\circ} \mathrm{C} / 75 \% \mathrm{RH}\right)$ of Pf remained compared with a day 0 baseline (Fig. 6c). When Pf released from a 1 month stored PNG was added to TGF- $\beta 1$-stimulated fibroblasts, $\alpha$-SMA expression was visibly reduced and biological activity was maintained (Supplemental 5).

\section{DISCUSSION}

In this work, we utilized DAC to emulsify a PNG composed of an aqueous phase containing P407 and an oil phase with high loading capacity for Pf as a topical vehicle for Pf. Triacetin was selected as an oil phase from a solubility screen in which Pf saturated at $7 \mathrm{w} / \mathrm{v} \%$ (Supplemental 6). While propylene glycol and polyethylene glycol 400 have higher saturation solubilities compared with triacetin, these solvents could not be emulsified with a P407 gel because of their hydrophilicity. We observed that a P407 concentration > $10 \mathrm{wt} \%$ resulted in a gel-like consistency, and we included P407 at a final concentration of $13.8 \mathrm{wt} \%$-lower than the $15 \mathrm{wt} \%$ maximum approve concentration in the FDA inactive ingredient database. Polysorbate 80 and benzyl alcohol are widely used pharmaceutical excipients and were used as a stabilizer and preservative, respectively. To emulsify this composition (Table I), we observed that DAC is very efficient and did not require long mix times.

To ensure that the processing and materials used in the PNG formulation did not diminish its established biological effect of Pf, we assayed the ability of the drug to inhibit human dermal myofibroblast differentiation. The persistence of highly contractile dermal myofibroblasts is a key feature of pathological scarring, such as hypertrophic scarring after burn injury (34). During wound healing, fibroblasts transform into contractile myofibroblasts upon exposure to TGF- $\beta 1$ released by activated platelets and immune cells in the wound bed (35). These myofibroblasts express the alpha-smooth muscle isoform of actin ( $\alpha$-SMA) in contractile F-actin stress fibers that allow for greater force production to rearrange and contract surrounding extracellular matrix. Pf has been shown to inhibit the development of the myofibroblast phenotype in TGF- $\beta 1$-treated normal human dermal fibroblasts in vitro by reducing the development of F-actin stress fibers and $\alpha$-SMA expression (21). We did not observe noticeable loss of either 
drug content or drug activity with 1 month of storage. This is consistent with reports that Pf is a stable active pharmaceutical ingredient with minimal breakdown observed during forced degradation conditions including extreme $\mathrm{pH}$, oxidation, light, and heat (36).

Additionally, we observed significant vehicle effects inhibiting human dermal myofibroblast differentiation. In support of these findings, poloxamers have been demonstrated to be protective in various injuries and pathologies including brain injury (25), rotator cuff injury (37), and cardiovascular disease (27), and can reduce fibrotic adhesions after surgery $(38,39)$. Most relevant to our goal of a topical burn treatment, poloxamers have been reported to repair cells after heat shock insult (39) and may be useful in treating burn injury (40). Studies demonstrating the protective and reparative effects of poloxamers have primarily been with poloxamer $188(27,41)$, but the broader poloxamer family has been demonstrated to have membrane repairing properties, including P407 used in our formulation (26). It is proposed that poloxamers function through direct insertion into phospholipid bilayer to either reseal damaged cell membranes or protect cells from damage by increasing membrane rigidity (26). Reduced membrane fluidity is likely to have significant consequences to cell signaling occurring at the plasma membrane with ultimate consequences to cytoskeletal structure and function $(42,43)$. This increase in membrane rigidity may partly explain the vehicle effects seen with TGF- $\beta 1$ treated dermal fibroblasts. In addition, poloxamers have been shown to negatively affect cell adhesion to a collagen substrate and cell aggregation (44,45). Myofibroblast formation requires the formation of large super mature focal adhesions to an extracellular matrix (46) and thus, may be affected by inhibition of this process by poloxamer. The mechanism of vehicle effects reducing $\alpha$-SMA expression in human dermal myofibroblasts was not directly interrogated in this study but would be an interesting subject for future investigation.

While drug activity was maintained, we observed negative trends in the stability of the PNG composition. We observed a large increase in droplet size within 1 week. Notably, when droplet size was measured by DLS, we consistently observed a peak size shift of shrinking diameter over time (data not shown), so we are reporting the dominant peak measured immediately after the PNG was diluted. We suspect small droplets produced initially under high shear forces quickly equilibrated with rest to a more stable droplet diameter. Fine emulsions have been demonstrated to have higher viscosities than coarse emulsions (32), and the measured increase in droplet size may partially contribute to the decrease in viscosity after 1 week.

Furthermore, with measured decreases in viscosity as well as pH of our current PNG composition (Fig. 6a-b), we hypothesize that poloxamer degradation is contributing to the changes. Poloxamers are A-B-A block copolymers consisting of ethylene oxide and propylene oxide and have been demonstrated to undergo oxidative degradation with byproducts of acetic acid and formic acid that correspond to drops in $\mathrm{pH}$ (47). As poloxamer is the gelling agent used in the PNG, poloxamer degradation would also be consistent with the decreases in viscosity, but additional tests must be run to identify degradation products and acid species. From
1 month stored samples, it is notable that changes in $\mathrm{pH}$ or viscosity did not affect the release profile of Pf which we believe is driven by passive diffusion. In order to address the observed instability, studies with antioxidants would directly assess whether poloxamer degradation is contributing to the change in $\mathrm{pH}$ and viscosity. We incorporated benzyl alcohol as a preservative/antioxidant in the formulation, but alternative antioxidants such as butylated hydroxytoluene (BHT) have been demonstrated to mitigate the degradation of poloxamer and could be an approach to improve formulation stability (47).

Alternatively, triacetin is known to have acid degradation byproducts, namely acetic acid (48). According to the Organization for Economic Co-operation and Development (OECD) assessment of triacetin, abiotic hydrolysis is observed in water with a half-life of 60.4 days at $\mathrm{pH} 7,25^{\circ} \mathrm{C}$, and is also susceptible to breakdown by biological enzymes (e.g., esterases) (33). However, limited hydrolysis is observed at lower $\mathrm{pH}$. With $\mathrm{pH}$ adjustment and inclusion of buffering agents to match the acidic $\mathrm{pH}$ of skin (49), excipient degradation may be mitigated in future studies.

The relevance and utility of DAC as a pharmaceutical mixing method is dependent on its ability to scale-up. As we have demonstrated in this work, DAC can efficiently emulsify and homogenously distribute drug for batch sizes ranging from 1.5 to $100 \mathrm{~g}$, the maximum limit of our current model. Output can potentially be scaled up to $5 \mathrm{~kg}$ using existing offthe-shelf DAC units, but a limitation of this mixing method is that it is currently capped to small-scale manufacturing efforts. This maximum batch size simply does not compete with traditional mixing methods that have capacities upwards of $10,000 \mathrm{~kg}$. Production scale-up is a non-unique challenge that must be regularly addressed in translating lab-scale formulations to pilot scale and eventually commercial scale manufacturing $(50,51)$. If $\mathrm{DAC}$ is used for compositional screening and lab-scale development of novel formulations with a goal of commercial scale, significant efforts must go into identification of an alternate mixing method which includes process development and validation $(52,53)$.

Although there are limitations on batch capacity of commercial scale, DAC-based formulation development may still translate well for specialized markets that utilize distributed manufacturing networks (54-56). For example, compounding pharmacies have taken on specialized services and treatments with local, small-scale production that centrally manufactured products cannot provide $(57,58)$. As personalized medicine demands more custom therapies, there have been notable examples of on-site manufacturing of drug products including tablets and implantable systems (59). With its many advantages previously discussed, DAC could prove valuable for rapid on-site production of not only PNGs, but a wide variety of pharmaceutical formulations.

\section{CONCLUSIONS}

We demonstrated that a short, single step mix time can efficiently emulsify a poloxamer-based gel with a triacetin oil phase and other excipients. Pf powder was simultaneously distributed homogeneously and solubilized through the vehicle during the emulsification process. Stepwise batch scale-up from 1.5 to $100 \mathrm{~g}$ showed comparable rheological 
properties although further process optimization may be undergone to improve drug homogeneity in larger batches. The composition or process method did not inhibit the in vitro biological activity of Pf. Although less effective compared with PNG-Pf, vehicle controls showed effects in reducing $\alpha$ SMA expression and myofibroblast development. However, the current composition requires selection of alternative antioxidants and/or $\mathrm{pH}$ modifier excipients to mitigate stability issues observed with drops in $\mathrm{pH}$ and viscosity when stored over time. In summary, these findings show that DAC is a rapid developmental tool for formulations and should be considered for broader formulation applications in the future.

\section{FUNDING INFORMATION}

This work was supported in part through the Congressionally Directed Medical Research Programs, US Army Medical Research and Development Command [W81XWH15-2-0083], and the Naval Medical Research Center's Advanced Medical Development program [MIPR N3239815MHX040].

\section{COMPLIANCE WITH ETHICAL STANDARDS}

Disclaimer The views expressed in this article (book, speech, etc.) are those of the author(s) and do not reflect the official policy or position of the U.S. Army Medical Department, Department of the Army, DoD, or the U.S. Government.

Open Access This article is licensed under a Creative Commons Attribution 4.0 International License, which permits use, sharing, adaptation, distribution and reproduction in any medium or format, as long as you give appropriate credit to the original author(s) and the source, provide a link to the Creative Commons licence, and indicate if changes were made. The images or other third party material in this article are included in the article's Creative Commons licence, unless indicated otherwise in a credit line to the material. If material is not included in the article's Creative Commons licence and your intended use is not permitted by statutory regulation or exceeds the permitted use, you will need to obtain permission directly from the copyright holder. To view a copy of this licence, visit http://creativecommons.org/licenses/by/4.0/.

\section{REFERENCES}

1. Vanderbilt D, Adams B, Walker K, Huang H, Ruscio D. Mixing and deareration of viscous materials. US20070002681A1, 2005.

2. Huang Z, Li X, Zhang T, Song Y, She Z, Li J, et al. Progress involving new techniques for liposome preparation. Asian J Pharm Sci. 2014;9:176-82. https://doi.org/10.1016/ j.ajps.2014.06.001.

3. Cullen PJ, Romañach RJ, Abatzoglou N, Rielly CD. Pharmaceutical blending and mixing. Chichester: Wiley; 2015. https:// doi.org/10.1002/9781118682692.

4. Massing U, Ingebrigtsen SG, Škalko-Basnet N, Holsæter AM. Dual centrifugation-a novel "in-vial" liposome processing technique. Liposomes: InTech; 2017. https://doi.org/10.5772/ intechopen.68523.

5. Hirsch M, Ziroli V, Helm M, Massing U. Preparation of small amounts of sterile siRNA-liposomes with high entrapping efficiency by dual asymmetric centrifugation (DAC). J Control Release. 2009;135:80-8. https://doi.org/10.1016/ j.jconrel.2008.11.029.

6. Sinkó B, Garrigues TM, Balogh GT, Nagy ZK, Tsinman O, Avdeef A, et al. Skin-PAMPA: a new method for fast prediction of skin penetration. Eur J Pharm Sci. 2012;45:698-707. https:// doi.org/10.1016/j.ejps.2012.01.011.

7. Martins PP, Estrada AD, Smyth HDC. A human skin highthroughput formulation screening method using a model hydrophilic drug. Int J Pharm. 2019;565:557-68. https://doi.org/ 10.1016/j.ijpharm.2019.05.044.

8. Jacobsen AC, Krupa A, Brandl M, Bauer-Brandl A. Highthroughput dissolution/permeation screening - a 96-well twocompartment microplate approach. Pharmaceutics. 2019;11. https://doi.org/10.3390/pharmaceutics11050227.

9. Massing U, Cicko S, Ziroli V. Dual asymmetric centrifugation (DAC) - a new technique for liposome preparation. J Control Release. 2008;125:16-24. https://doi.org/10.1016/ j.jconrel.2007.09.010.

10. Tian W, Schulze S, Brandl M, Winter G. Vesicular phospholipid gel-based depot formulations for pharmaceutical proteins: development and in vitro evaluation. J Control Release. 2010;142:319-25. https://doi.org/10.1016/j.jconrel.2009.11.006.

11. Ingebrigtsen SG, Škalko-Basnet N, Holsæter AM. Development and optimization of a new processing approach for manufacturing topical liposomes-in-hydrogel drug formulations by dual asymmetric centrifugation. Drug Dev Ind Pharm. 2016;42:137583. https://doi.org/10.3109/03639045.2015.1135940.

12. Tenambergen F, Maruiama CH, Mäder K. Dual asymmetric centrifugation as an alternative preparation method for parenteral fat emulsions in preformulation development. Int J Pharm. 2013;447:31-7. https://doi.org/10.1016/j.ijpharm.2013.02.033.

13. Kreuter M. Pirfenidone: An update on clinical trial data and insights from everyday practice. Eur Respir Rev. 2014;23:111-7. https://doi.org/10.1183/09059180.00008513.

14. Mandapalli PK, Labala S, Bojja J, Venuganti VVK. Effect of pirfenidone delivered using layer-by-layer thin film on excisional wound healing. Eur J Pharm Sci. 2016;83:166-74. https:// doi.org/10.1016/j.ejps.2015.12.027.

15. Jose A, Mandapalli PK, Venuganti VVK. Liposomal hydrogel formulation for transdermal delivery of pirfenidone. J Liposome Res. 2016;26:139-47. https://doi.org/10.3109/ 08982104.2015 .1060611$.

16. Rodríguez-Castellanos M, Tlacuilo-Parra A, Sánchez-Enríquez S, Vélez-Gómez E, Guevara-Gutiérrez E. Pirfenidone gel in patients with localized scleroderma: a phase II study. Arthritis Res Ther. 2014;16:510. https://doi.org/10.1186/s13075-014-05104.

17. Janka-Zires M, Almeda-Valdes P, Uribe-Wiechers AC, JuárezComboni Sonia C, López-Gutiérrez J, Escobar-Jiménez JJ, et al. Topical administration of pirfenidone increases healing of chronic diabetic foot ulcers: a randomized crossover study. J Diabetes Res. 2016;2016:1-7. https://doi.org/10.1155/2016/ 7340641.

18. Lopez-de la Mora DA, Sanchez-Roque C, Montoya-Buelna M, Sanchez-Enriquez S, Lucano-Landeros S, Macias-Barragan J, et al. Role and new insights of pirfenidone in fibrotic diseases. Int J Med Sci. 2015;12:840-7. https://doi.org/10.7150/ijms.11579.

19. Shi K, Wang F, Xia J, Zuo B, Wang Z, Cao X. Pirfenidone inhibits epidural scar fibroblast proliferation and differentiation by regulating TGF- $\beta 1$-induced Smad-dependent and independent pathways. Am J Transl Res. 2019;11:1593-604.

20. Wang J, Yang Y, Xu J, Lin X, Wu K, Yu M. Pirfenidone inhibits migration, differentiation, and proliferation of human retinal pigment epithelial cells in vitro. Mol Vis. 2013;19:2626-35.

21. Hall CL, Wells AR, Leung KP. Pirfenidone reduces profibrotic responses in human dermal myofibroblasts, in vitro. Lab Investig. 2018;98:640-55. https://doi.org/10.1038/s41374-0170014-3.

22. Macías-Barragán J, Sandoval-Rodríguez A, Navarro-Partida J, Armendáriz-Borunda J. The multifaceted role of pirfenidone 
and its novel targets. Fibrogenesis Tissue Repair. 2010;3:16. https://doi.org/10.1186/1755-1536-3-16.

23. Wells AR, Leung KP. Pirfenidone attenuates the profibrotic contractile phenotype of differentiated human dermal myofibroblasts. Biochem Biophys Res Commun. 2020;521:64651. https://doi.org/10.1016/j.bbrc.2019.10.177.

24. Medina JL, Sebastian EA, Fourcaudot AB, Dorati R, Leung KP. Pirfenidone ointment modulates the burn wound bed in C57BL/6 mice by suppressing inflammatory responses. Inflammation. 2019;42:45-53. https://doi.org/10.1007/s10753-018-0871y.

25. Curry DJ, Wright DA, Lee RC, Kang UJ, Frim DM. Surfactant poloxamer 188-related decreases in inflammation and tissue damage after experimental brain injury in rats. J Neurosurg. 2004;101:91-6. https://doi.org/10.3171/ped.2004.101.2.0091.

26. Kwiatkowski TA, Rose AL, Jung R, Capati A, Hallak D, Yan $\mathrm{R}$, et al. Multiple poloxamers increase plasma membrane repair capacity in muscle and nonmuscle cells. Am J Phys Cell Phys. 2020;318:C253-62. https://doi.org/10.1152/ajpcell.00321.2019.

27. Moloughney JG, Weisleder N. Poloxamer 188 (P188) as a membrane resealing reagent in biomedical applications. Recent Pat Biotechnol. 2013;6:200-11. https://doi.org/10.2174/ 1872208311206030200.

28. Bodratti AM, Alexandridis P. Formulation of poloxamers for drug delivery. J Funct Biomater. 2018;9. https://doi.org/10.3390/ jfb9010011.

29. Murdan S. A review of pluronic lecithin organogel as a topical and transdermal drug delivery system 2005 .

30. Almeida H, Amaral MH, Lobão P, Lobo JMS. Pluronic ${ }^{\circledR}$ F-127 and pluronic lecithin organogel (PLO): main features and their applications in topical and transdermal administration of drugs. J Pharm Pharm Sci. 2012;15:592-605. https://doi.org/10.18433/ j3hw2b.

31. Harris VM. Protein detection by simple western ${ }^{\mathrm{TM}}$ analysis. West. Blotting Methods Protoc., vol. 1312. New York: Springer; 2015. p. 465-8. https://doi.org/10.1007/978-1-4939-2694-7_47.

32. Pal R. Effect of droplet size on the rheology of emulsions. AIChE J. 1996;42:3181-90. https://doi.org/10.1002/ aic.690421119.

33. Triacetin. Boston: 2002.

34. Gauglitz GG, Korting HC, Pavicic T, Ruzicka T, Jeschke MG. Hypertrophic scarring and keloids: Pathomechanisms and current and emerging treatment strategies. Mol Med. 2011;17:113-25. https://doi.org/10.2119/molmed.2009.00153.

35. Hinz B. Formation and function of the myofibroblast during tissue repair. J Invest Dermatol. 2007;127:526-37. https://doi.org/ 10.1038/sj.jid.5700613.

36. CHMP assessment Report, Esbriet. London; 2010.

37. Kim TI, Jung W, Chung JY, Jeong H, Kim SH. Effect of a poloxamer-based thermosensitive gel on rotator cuff repair in a rabbit model: a controlled laboratory study. J Orthop Surg Res. 2019;14:190. https://doi.org/10.1186/s13018-019-1246-2.

38. Sohn EJ, Ahn HB, Roh MS, Ryu WY, Kwon YH. Efficacy of temperature-sensitive guardix-sg for adhesiolysis in experimentally induced eyelid adhesion in rabbits. Ophthal Plast Reconstr Surg. 2013;29:458-63. https://doi.org/10.1097/ IOP.0b013e3182a22bae.

39. Merchant FA, Holmes WH, Capelli-Schellpfeffer M, Lee RC, Toner M. Poloxamer 188 enhances functional recovery of lethally heat-shocked fibroblasts. J Surg Res. 1998;74:131-40. https://doi.org/10.1006/jsre.1997.5252.

40. Dalal ND, Lee RC. Treatment of burn injury by cellular repair. J Craniofac Surg. 2008;19:903-6. https://doi.org/10.1097/ SCS.0b013e318175b541.

41. Sharma V, Stebe K, Murphy JC, Tung L. Poloxamer 188 decreases susceptibility of artificial lipid membranes to electroporation. Biophys J. 1996;71:3229-41. https://doi.org/10.1016/ S0006-3495(96)79516-4.
42. Clarke MSF, Prendergast MA, Terry AV. Plasma membrane ordering agent pluronic F-68 (PF-68) reduces neurotransmitter uptake and release and produces learning and memory deficits in rats. Learn Mem. 1999;6:634-49. https://doi.org/10.1101/ $\operatorname{lm} .6 .6 .634$.

43. Kalappurakkal JM, Anilkumar AA, Patra C, van Zanten TS, Sheetz MP, Mayor S. Integrin Mechano-chemical signaling generates plasma membrane nanodomains that promote cell spreading. Cell. 2019;177:1738-1756.e23. https://doi.org/10.1016/ j.cell.2019.04.037.

44. Tan J, Saltzman WM. Influence of synthetic polymers on neutrophil migration in three-dimensional collagen gels. J Biomed Mater Res. 1999;46:465-74. https://doi.org/10.1002/ (sici)1097-4636(19990915)46:4<465::aid-jbm4>3.0.co;2-n.

45. Owen E, Clifford JD, Marson AP. The effects of surfactants on cell aggregation. J Cell Sci. 1978;32:363-76.

46. Goffin JM, Pittet P, Csucs G, Lussi JW, Meister JJ, Hinz B. Focal adhesion size controls tension-dependent recruitment of $\alpha$-smooth muscle actin to stress fibers. J Cell Biol. 2006;172:25968. https://doi.org/10.1083/jcb.200506179.

47. Erlandsson B. Erlandsson B, stability-indicating changes in poloxamers, the degradation of ethylene oxide-propylene oxide block copolymers at 25 and 40C. Polym Degrad Stab. 2002;78:571-5. https://doi.org/10.1002/masy.19890270109.

48. Laino T, Tuma C, Moor P, Martin E, Stolz S, Curioni A. Mechanisms of propylene glycol and triacetin pyrolysis. J Phys Chem A. 2012;116:4602-9. https://doi.org/10.1021/jp300997d.

49. Fürtjes T, Weiss KT, Filbry A, Rippke F, Schreml S. Impact of a pH 5 oil-in-water emulsion on skin surface pH. Skin Pharmacol Physiol 2018;30:292-297. https://doi.org/10.1159/000480300.

50. Levin M. Editor. Pharmaceutical process scale-up. 3rd ed. Marcel Dekker, Inc: New York; 2001.

51. van Heugten AJP, Vromans H. Scale up of semisolid dosage forms manufacturing based on process understanding: from lab to industrial scale. AAPS PharmSciTech. 2018;19:2330-4. https://doi.org/10.1208/s12249-018-1063-7.

52. Raval N, Tambe V, Maheshwari R, Deb PK, Tekade RK. Scaleup studies in pharmaceutical products development. Dos. Form Des. Considerations: Elsevier; 2018. p. 669-700. https://doi.org/ 10.1016/b978-0-12-814423-7.00019-8.

53. Block LH. Scale up of a liquid and semisolid manufacturing process. Pharm Technol. 2005:26-33.

54. Srai JS, Kumar M, Graham G, Phillips W, Tooze J, Ford S, et al. Distributed manufacturing: scope, challenges and opportunities. Int J Prod Res. 2016;54:6917-35. https://doi.org/10.1080/ 00207543.2016.1192302.

55. Içten E, Purohit HS, Wallace C, Giridhar A, Taylor LS, Nagy ZK, et al. Dropwise additive manufacturing of pharmaceutical products for amorphous and self emulsifying drug delivery systems. Int J Pharm. 2017;524:424-32. https://doi.org/10.1016/ j.ijpharm.2017.04.003.

56. Rauch E, Dallasega P, Matt DT. Distributed manufacturing network models of smart and agile mini-factories. Int J Agil Syst Manag. 2017;10:185. https://doi.org/10.1504/IJASM.2017.088534.

57. Dooms M, Carvalho M. Compounded medication for patients with rare diseases. Orphanet J Rare Dis. 2018;13. https://doi.org/ 10.1186/s13023-017-0741-y.

58. Giam JA, McLachlan AJ, Krass I. Characterizing specialized compounding in community pharmacies. Res Soc Adm Pharm. 2012;8:240-52. https://doi.org/10.1016/j.sapharm.2011.05.003.

59. Zema L, Melocchi A, Maroni A, Gazzaniga A. Threedimensional printing of medicinal products and the challenge of personalized therapy. J Pharm Sci. 2017;106:1697-705. https:// doi.org/10.1016/j.xphs.2017.03.021.

Publisher's Note Springer Nature remains neutral with regard to jurisdictional claims in published maps and institutional affiliations. 